\title{
Printer Nir Kabel
}

\author{
Budihardja Murtianta \\ Program Studi Teknik Elektro, \\ Fakultas Teknik Elektronika dan Komputer, \\ Universitas Kristen Satya Wacana, Salatiga \\ budihardja.murtianta@staff.uksw.edu
}

\section{Ringkasan}

Printer Nir Kabel dengan Amplitude Shift Keying merupakan salah satu solusi pengganti kabel atau infrared link yang menghubungkan piranti yang satu dengan piranti yang lainnya menggunakan gelombang elektromagnetik. Pada tulisan ini dirancang dan direalisasikan sebuah printer nir kabel dengan Amplitude Shift Keying (ASK) menggunakan mikrokontroler AT89S52 sebagai basis pengendaliannya. Alat ini dapat digunakan pada printer yang berbasiskan parallel port. Dengan alat ini komputer dapat terhubung dengan printer secara nir kabel. Port komputer yang dapat digunakan untuk aplikasi ini adalah paralel. Modul ASK TLP434 dan RLP434 masih dapat bekerja dengan baik pada jarak 14 meter dengan kondisi tanpa halangan dan di dalam gedung.

Kata kunci: Amplitude Shift Keying, nir kabel, elektromagnetik

\section{Pendahuluan}

Kabel printer parallel yang biasa dipakai hanya memiliki panjang sekitar satu hingga dua meter. Jadi dalam pemakaiannya akan dibatasi oleh panjang kabel. Penambahan kabel sendiri memiliki batasan, dalam arti untuk kabel yang terlalu panjang akan menyebabkan lemahnya sinyal-sinyal yang dikirim menuju printer dan akhirnya bisa menyebabkan terjadinya kesalahan dalam pencetakan.

Teknologi pengiriman data saat ini berkembang ke arah nir kabel, antara lain dengan menggunakan gelombang radio, infra merah, dan sebagainya. Amplitude Shift Keying (ASK) merupakan salah satu teknologi transmisi data yang memanfaatkan gelombang radio untuk pengiriman data. Pemakaian gelombang radio sebagai media transmisi data atau komunikasi antara komputer dengan printer disini memiliki keunggulan dalam mengatasi permasalahan jarak di atas.

Dalam dunia industri, port paralel komputer (LPT) masih mempunyai peranan penting dalam komunikasi data antara divais komputer dengan divais yang lain, meskipun sistem baru seperti USB (Universal Serial Bus), ethernet berkembang dengan pesat. Banyak divais menggunakan port $D B-25$ untuk mentransfer dan memperoleh data dari komputer untuk diolah. Bila sering melakukan transfer data dan letak sumber data susah dijangkau karena terganggu kabel, Amplitude Shift Keying (ASK) menawarkan solusi sebagai pengganti kabel.

Karena keunggulan tersebut, maka diharapkan mampu mengurangi ketergantungan terhadap kabel serta memberikan gambaran tentang cara kerja Amplitude Shift Keying (ASK) sebagai pengganti kabel, sehingga dapat diaplikasikan untuk sistem yang lain. 


\section{Dasar Teori}

\subsection{Pengendali-Mikro AT89S52}

Pengendali-mikro yang digunakan adalah AT89S52 buatan ATMEL yang masih tergolong dalam keluarga MCS-51. Pengendali-mikro AT89S52 memiliki memori internal Programmable and Erasable Read Only Memory (PEROM) sebesar 4 Kbyte, sehingga perangkat lunak yang dibuat dapat langsung disimpan di dalam $R O M$ internal yang ada. Spesifikasi teknis dari pengendali-mikro AT89S52 adalah sebagai berikut:

1. 256 byte $x 8$ internal RAM.

2. 8 Kbyte reprogrammable flash memori.

3. 3 buah timer/counter 16 bit.

4. Saluran serial programmable.

5. Sebuah port serial dengan pengendalian serial full duplex UART ( Universal Asynchronous Receiver/ Transmitter).

6. 8 buah jalur interupsi.

7. Port I/O memiliki lebar 8 bit yang dapat difungsikan sebagai input/output

Pengendali-mikro AT89S52 memiliki 40 pena yang terbagi dalam empat buah port $\mathrm{I} / \mathrm{O}$ (port 0 , port 1 , port 2 dan port 3 ) serta beberapa pena tambahan yang memiliki fungsi tertentu. Blok diagramnya adalah seperti pada Gambar 1.

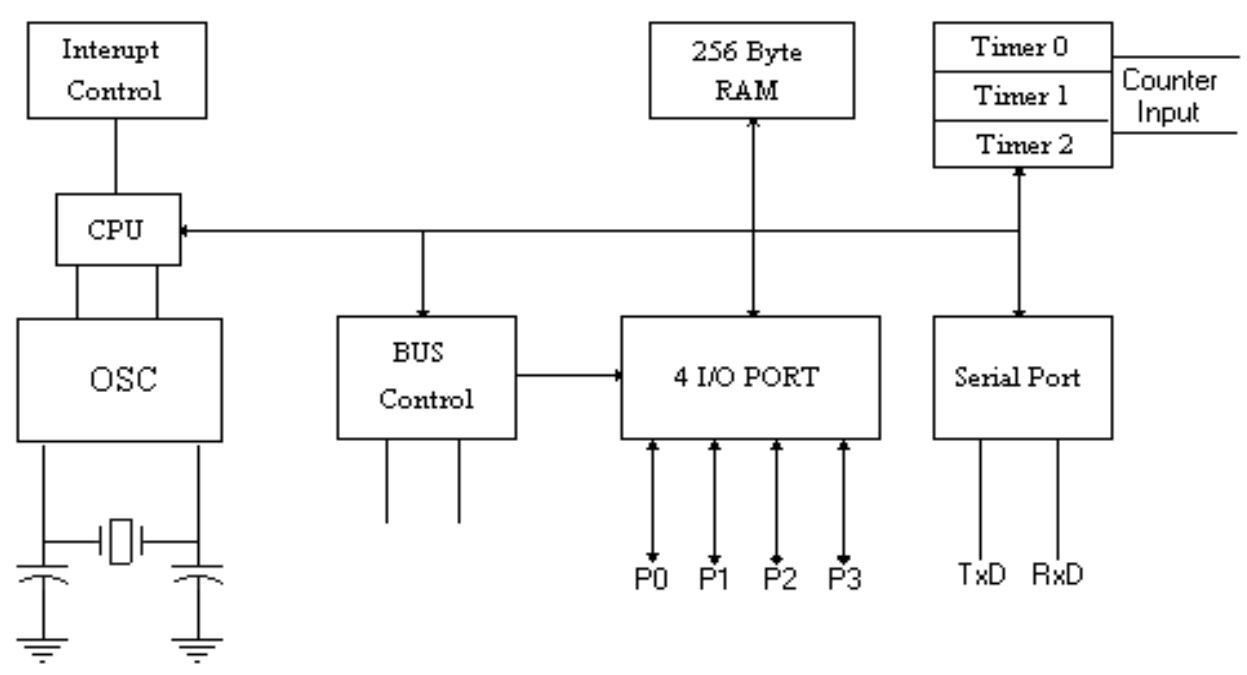

Gambar 1. Blok Diagram Pengendali-mikro AT89S52

\subsection{Paralel Port Komputer}

Untuk berhubungan dengan alat lain, komputer diberi tambahan berupa Parallel port dan serial port. Konektor Parallel port terletak dibelakang komputer. Pada parallel port data dikirimkan 8 bit bersamaan sehingga data dapat dikirimkan dengan cepat. Kebanyakan parallel port menggunakan konektor DB 25. Parallel port terletak pada video adapter atau di multi I/O card. Tiap komponen dalam komputer menempati alamat yang berbeda. Parallel port pada komputer diberi nama LPT0, LPT1, dan LPT2 yang memiliki alamat sendirisendiri. 
Standard Parallel Port menggunakan status dan kontrol bit untuk handshaking dengan peripheral. Gambar 2 menunjukkan handshaking dan sinyal data untuk Standard Parallel Port. Langkah langkah pengiriman data Standard Parallel Port seperti di bawah ini.

1. PC membuat pin select-in low untuk memberitahu peripheral, PC akan melakukan komunikasi, peripheral menanggapinya dengan membuat pin select high. PC kemudian membaca status port dan memastikan bahwa pin select high, pin busy low, pin paper error low, dan pin error high.

2. Ketika semua status tidak ada masalah, PC akan menulis data pada jalur data D0D7.

3. Setelah $0,75 \mu \mathrm{s}$ PC akan membuat sinyal strobe menjadi low dengan lebar pulsa 1 sampai $5 \mu$ s. PC meng-hold data tersebut selama 0,75 $\mu$ s setelah strobe high.

4. Pada saat falling edge sinyal strobe, peripheral membaca data dan memberikan sinyal high pada pin busy.

5. Ketika peripheral selesai membaca data akan membangkitkan sinyal low pada pin Ack untuk memberitahu PC bahwa peripheral telah menerima data.

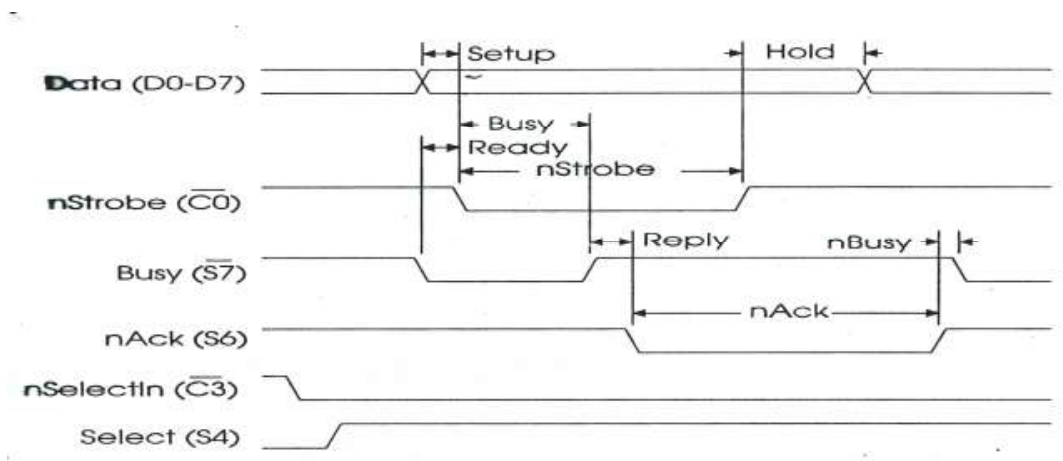

Gambar 2. Handshaking Standard Parallel Port.

\subsection{Komunikasi Serial}

Dalam komunikasi serial, data dikirim dalam bentuk pulsa listrik kontinyu yang disebut bit. Data dikirim satu demi satu melalui kanal komunikasi yang telah dipilih. Penerima juga menerima data dalam bentuk bit-bit pulsa listrik yang kontinyu. Ada 3 metode yang sering kita jumpai dalam komunikasi serial yaitu simpleks, half dupleks, dan full dupleks. Pada transmisi simpleks, data hanya dapat dikirim ke satu arah. Pada transmisi half dupleks, data dapat ditransmisikan dalam dua arah secara bergantian. Dan pada transmisi full dupleks merupakan transmisi dua arah dimana data dapat diterima oleh sistem secara bersamaan pada waktu bersamaan juga. Dalam teknik komunikasi asinkron, serial output line selalu ada pada logika " 1 " yang dinamakan marking. Setiap karakter dimulai dengan satu bit logika "0". Bit yang pertama ini dinamakan start bit dan digunakan untuk sinkronisasi antara pengirim dan penerima. Gambar 3. menunjukkan bentuk umum format data komunikasi serial asinkron. 


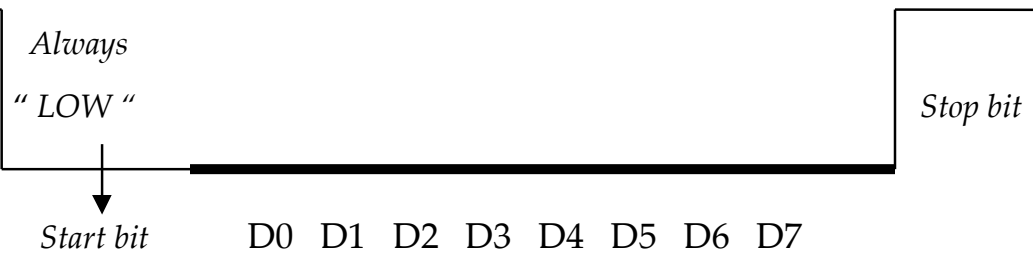

Gambar 3. Format Data Komunikasi Serial Asinkron.

Setelah start bit, dikirim bit-bit data satu-persatu yang dimulai dengan Least Significant Bit (LSB). Setelah bit data terkirim, satu atau dua bit logika "1" digunakan untuk menunjukkan bahwa data satu karakter sudah berakhir. Bit-bit ini dinamakan stop bit.

\subsection{Amplitude Shift Keying (ASK)}

Pembangkitan gelombang AM dapat dilakukan dengan dua pendekatan berbeda. Pertama adalah dengan membangkitkan sinyal AM secara langsung tanpa harus dengan membentuk sinyal base band. Sehingga dalam kasus biner, generator harus mampu memformulasi satu dari dua sinyal gelombang AM yang mungkin. Teknik ini lebih dikenal dengan amplitude shift keying (ASK), yang secara langsung menggambarkan suatu teknik modulasi digital. Yang kedua dengan menggunakan sinyal base band untuk memodulasi amplitudo suatu sinyal carrier yang dalam hal ini merupakan sinyal sinusoida (baik cos maupun sinus), seringkali ini dikenali sebagai AM analog dengan informasi dalam bentuk digital. Kedua teknik ini merupakan pembangkitan gelombang AM untuk mentransmisi informasi digital. Untuk selanjutnya keduanya diketahui sebagai dua bentuk pembentukan ASK atau lebih pahami sebagai AM digital.

Pada Gambar 4. terlihat sebuah situasi dimana sinyal base band yang ditransmisi memiliki dua kemungkinan nilai informasi yaitu antara nol (0) dan satu (1). Karena kemungkinan nilai informasinya tersusun dari dua keadaan tersebut maka selanjutnya sistem ini dikenal dengan binary ASK atau BASK yang merupakan singkatan dari binary amplitude shift keying.

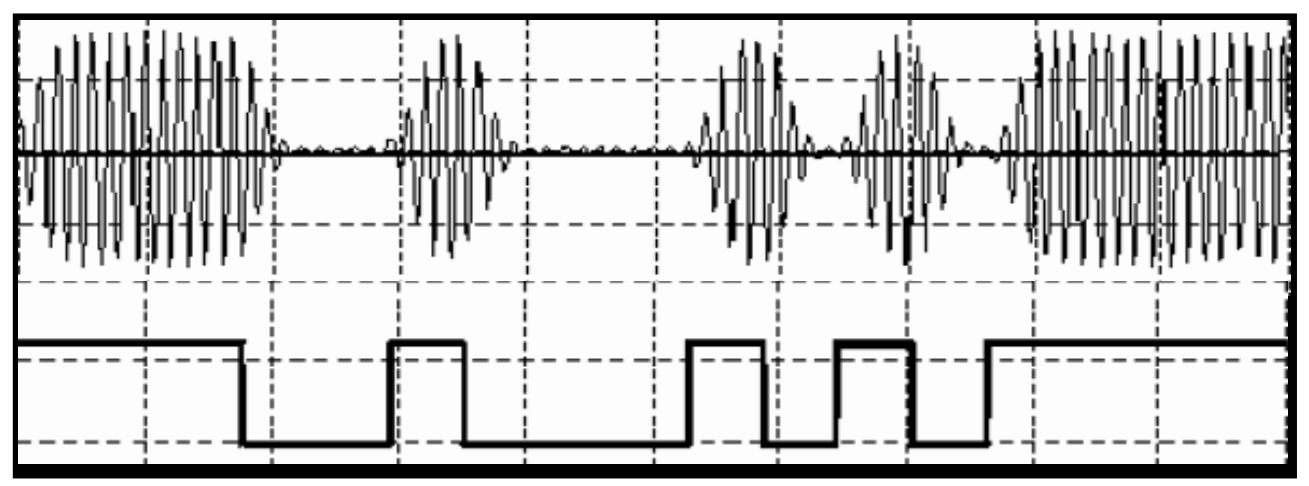

Gambar 4. Amplitude Shift Keying.

Amplitude Shift Keying (ASK) merupakan penggeseran amplitudo carier sesuai pola bit 0 dan 1 pada data. Proses modulation terjadi pada bagian pengiriman pada sistem komunikasi radio. Sedangkan pada bagian penerima terjadi proses demodulation. 


\section{Bagan kotak dari sistem wireless printer}

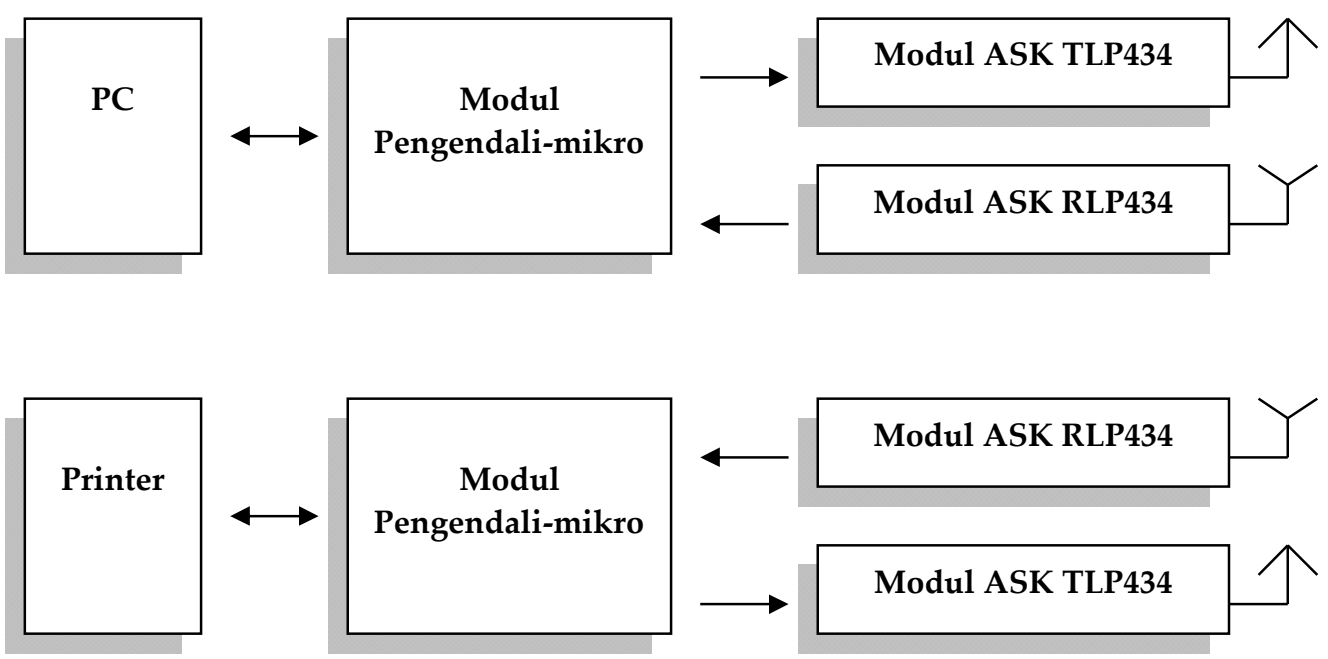

Gambar 5. Bagan Kotak Wireless Printer.

Perancangan dan realisasi perangkat keras dibagi menjadi beberapa bagian yaitu :

1. Bagian pengendali-mikro yang terhubung dengan komputer.

2. Bagian pengendali-mikro yang terhubung dengan printer.

3. Bagian modul ASK.

\subsection{Bagian Pengendali-mikro yang Terhubung dengan Komputer}

Pengendali-mikro bertugas untuk mengubah data paralel menjadi serial dan melakukan proses handshaking dengan parallel port sehingga seolah-olah komputer menganggap terdapat printer yang terkoneksi dengan parallel port. Data yang diterima oleh pengendali-mikro, kemudian dikirimkan menuju modul Amplitude Shift Keying (ASK) melalui port serial pengendali-mikro. Data dari parallel port komputer diambil oleh port 0 pengendali-mikro, kemudian dikirimkan secara serial ke printer melalui modul Amplitude Shift Keying (ASK). Sedangkan sinyal strobe dari komputer dihubungkan dengan INT 0 pada pengendali-mikro sehingga jika sinyal strobe menjadi low maka pengendali-mikro bisa mendeteksi adanya data baru. Pin 10 parallel port yang berupa acknowledge dihubungkan dengan P2.3 pengendali-mikro untuk merespon komputer bahwa data telah diambil. Pin 11 parallel port yang berupa busy dihubungkan dengan P2.2 pengendali-mikro untuk memberikan status busy pada komputer saat pengendali-mikro mengambil data. Agar komputer mendeteksi tidak ada masalah dengan kertas, maka P2.1 pengendali-mikro yang terhubung dengan pin 12 (paper error) memberikan sinyal high, pin 13 parallel port yang berupa select dihubungkan dengan P2.0 pengendali-mikro. Dalam hal ini P2.0 di atur high agar komputer menganggap pengendali-mikro sebagai printer.

Pada perancangan ini pembangkit frekuensi yang digunakan oleh pengendali-mikro AT89S52 adalah osilator XTAL $11.0592 \mathrm{MHz}$. Hal ini dimaksudkan agar kesalahan baud rate tidak terjadi dibandingkan dengan menggunakan kristal $12 \mathrm{MHz}$. Gambar koneksi pengendali-mikro dengan parallel port komputer yang direalisasikan terlihat pada Gambar 6. 

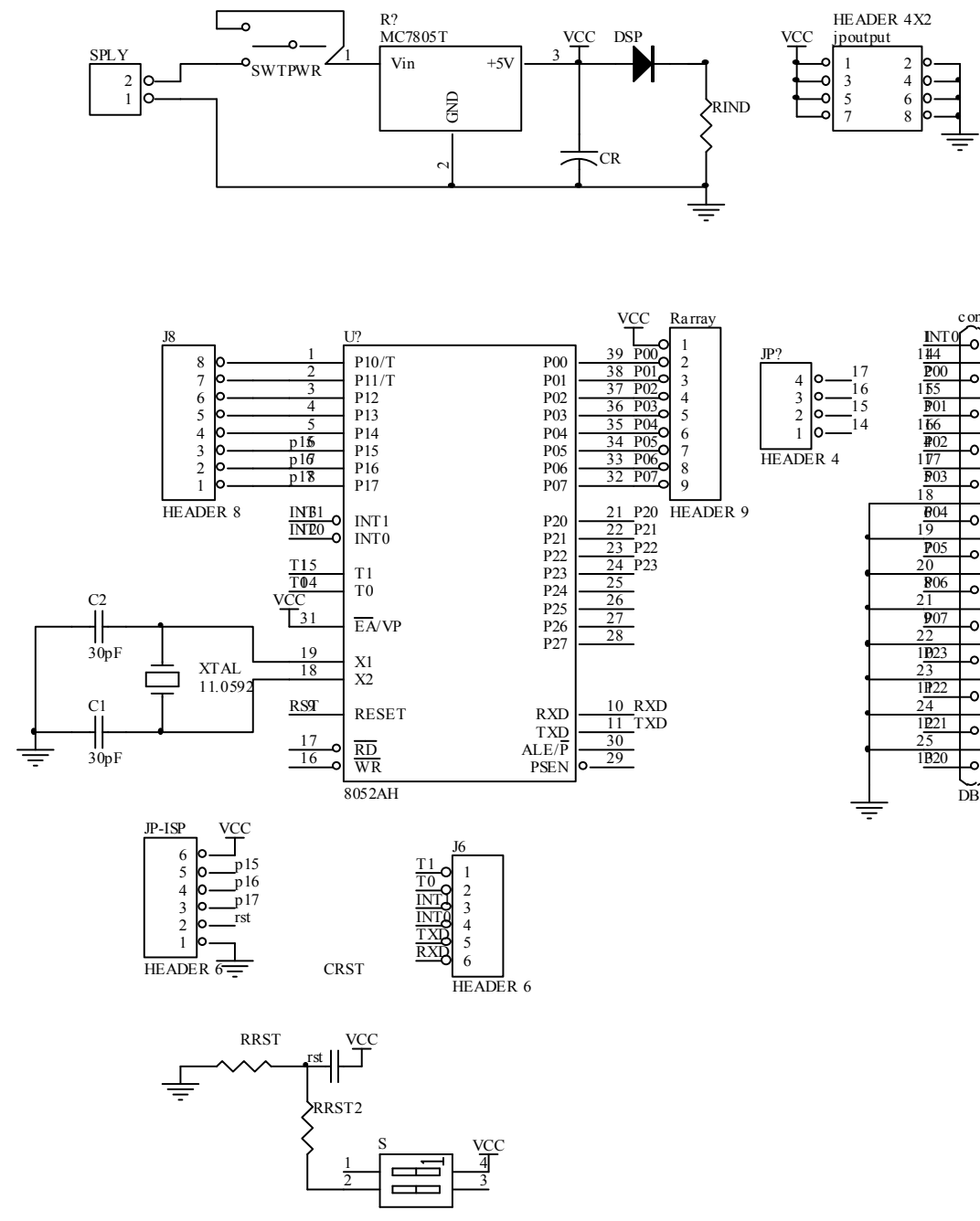

Gambar 6. Koneksi pengendali-mikro dengan Parallel port Komputer.

\subsection{Bagian pengendali-mikro yang Terhubung dengan Printer}

Bagian pengendali-mikro menuju printer hampir sama dengan bagian pengendalimikro menuju komputer, yang membedakan adalah perangkat lunaknya. Sistem pengendali-mikro yang terhubung dengan printer ditunjukkan pada Gambar 7.

Komunikasi wireless biasanya selalu dilakukan dengan komunikasi asinkron yaitu sebuah transmisi serial yang diawali dengan start bit dan diakhiri stop bit. Maka dari itu sistem yang terhubung pada parallel port komputer harus dapat mengubah data dari parallel port komputer menjadi serial asinkron dan sistem yang terhubung pada printer mengubah data serial asinkron menjadi paralel sesuai yang dibutuhkan oleh printer. 
Printer Nir Kabel

Budihardja Murtianta
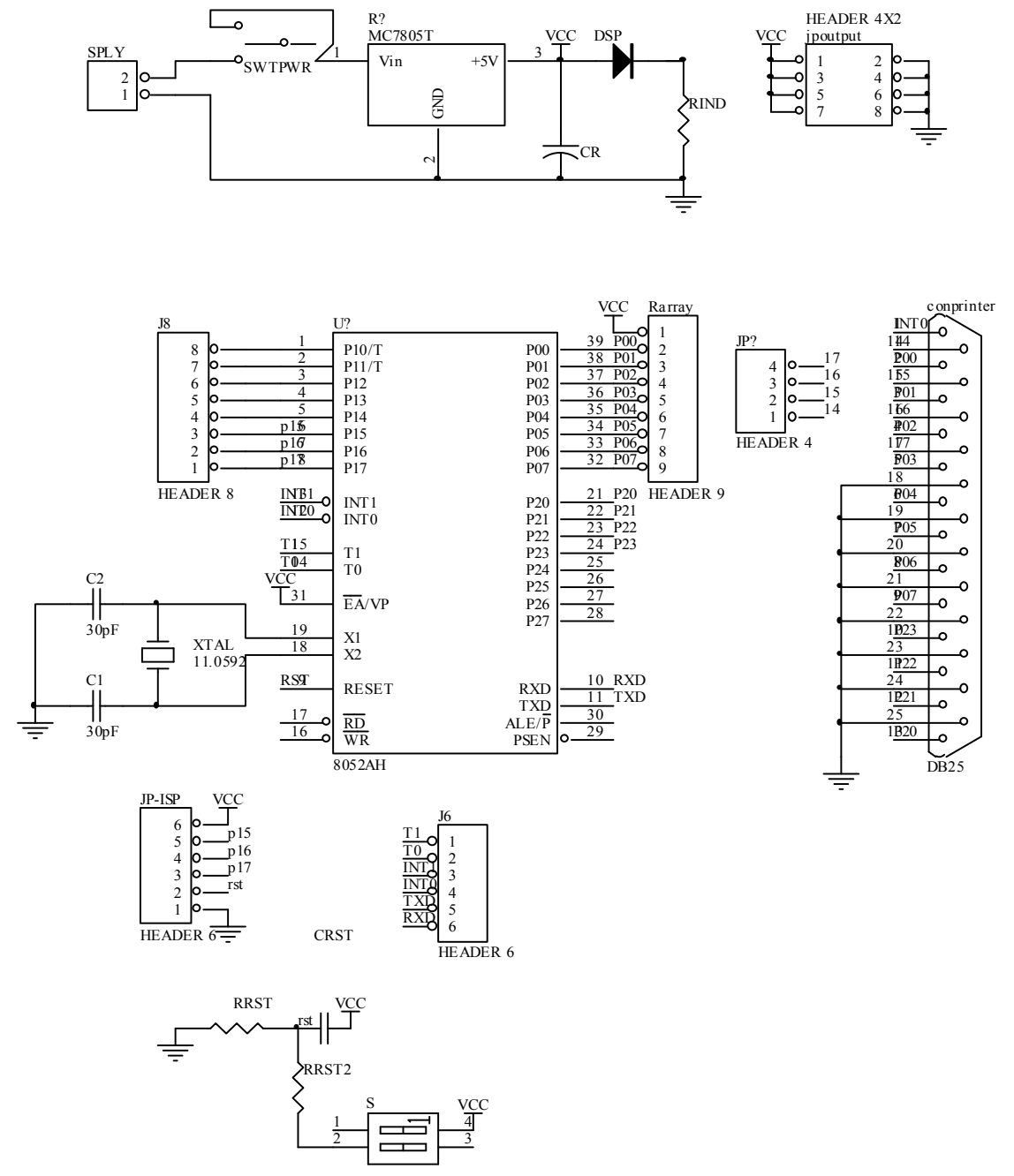

Gambar 7. Koneksi Pengendali-mikro dengan Printer.

Data yang diterima port serial pengendali-mikro diubah oleh pengendali-mikro menjadi data paralel agar dapat diterima oleh printer. Pengendali-mikro mengeluarkan data pada port 0 , dengan terlebih dahulu memeriksa kondisi printer apakah ready atau tidak dengan melihat status pin 13 parallel port. Data dikirimkan ke printer melalui port 0 dan diakhiri dengan sinyal strobe, sebagai tanda printer bahwa data telah siap untuk diambil.

\subsection{Modul ASK}

Bagian modul direalisasikan dengan menggunakan modul ASK TLP434 sebagai transmitter dan modul ASK RLP434 sebagai receiver. Modul Amplitude Shift Keying (ASK) buatan LAIPAC ini sering sekali digunakan sebagai alat untuk komunikasi data secara wireless menggunakan media udara. Masukan modul TLP4334 dan keluaran modul 
RLP434 berupa data serial. Jarak pancar maksimum dari modul ASK TLP434 sebagai transmitter dan modul ASK RLP434 sebagai receiver ini adalah 100 meter jika tanpa halangan dan 30 meter di dalam gedung. Jarak tersebut dapat dipengaruhi oleh faktor antena, kebisingan, dan tegangan kerja dari pemancar. Input pada modul ASK TLP434 dihubungkan dengan pena P3.1 (TxD) pada pengendali-mikro. Gambar rangkaian modul ASK TLP434 dapat dilihat pada Gambar 8.

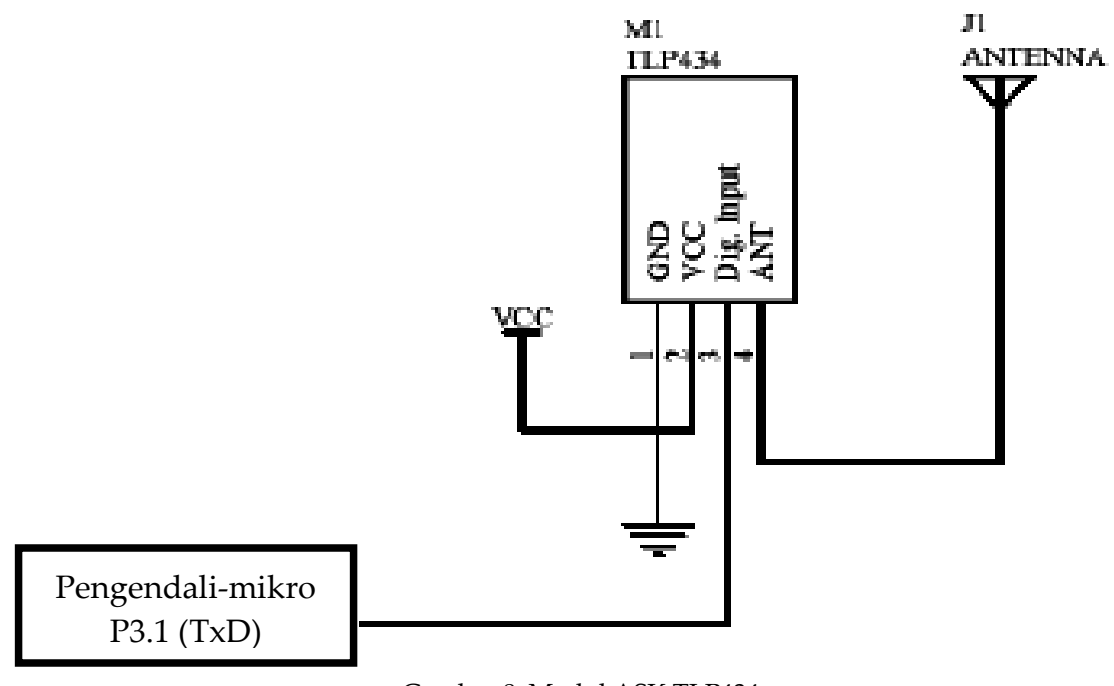

Gambar 8. Modul ASK TLP434.

Output modul ASK RLP434 dihubungkan dengan pena P3.0 (RxD) pada pengendalimikro yang kemudian akan diubah menjadi data paralel. Gambar rangkaian modul ASK RLP434 dapat dilihat pada Gambar 9.

\section{M2}

RLP434

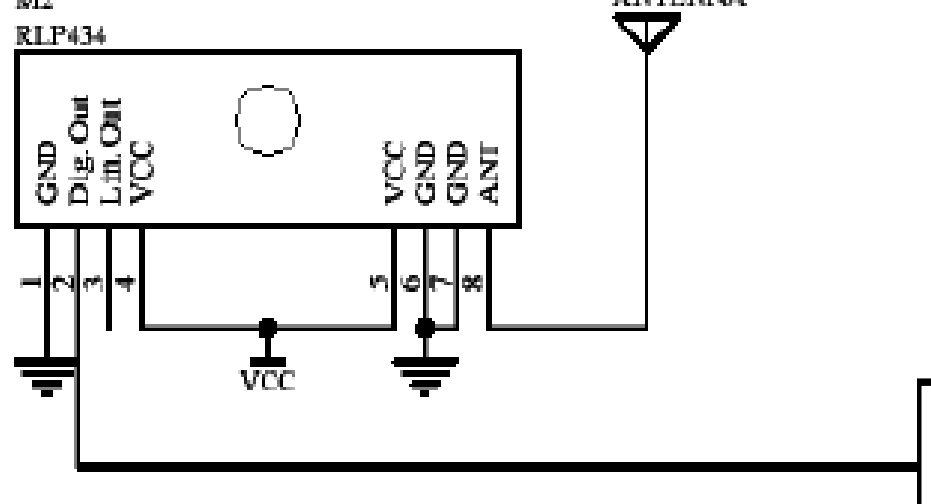

Gambar 9. Modul ASK RLP434.
Pengendalimikro P3.0

\section{Perangkat Lunak}

Perancangan dan perealisasian perangkat lunak dibagi menjadi dua bagian yaitu bagian pengambilan data dari parallel port dan bagian pengiriman data ke printer. Perangkat lunak digunakan untuk pengambilan data parallel port mengubahnya menjadi 
data serial, pengiriman data melalui modul Amplitude Shift Keying (ASK) dan pengubahan data serial menjadi paralel serta pengiriman data paralel ke printer dengan diakhiri sinyal strobe.

\subsection{Pengambilan Data dari Parallel Port}

Dalam pengambilan data dari port paralel komputer, pengendali-mikro pertamatama melakukan inisialisasi awal untuk mengatur inisialisasi port serial bekerja pada mode 1. Inisialisasi ini terdiri dari pengaturan sistem internal pengendali-mikro dan pengaturan sistem handshaking agar komputer mendeteksi adanya printer yang terpasang di parallel port. Modul Amplitude Shift Keying (ASK) TLP434 dan RLP434 memiliki baud rate $4,8 \mathrm{KHz}$, sehingga inisialisasi port serial pengendali-mikro diatur agar mempunyai baud rate 4,8 KHz. Pengaturan baud rate dilakukan dengan mengubah nilai pada Timer 1 (Th1). Diagram alir pengambilan data dari parallel port dapat dilihat pada Gambar 10.

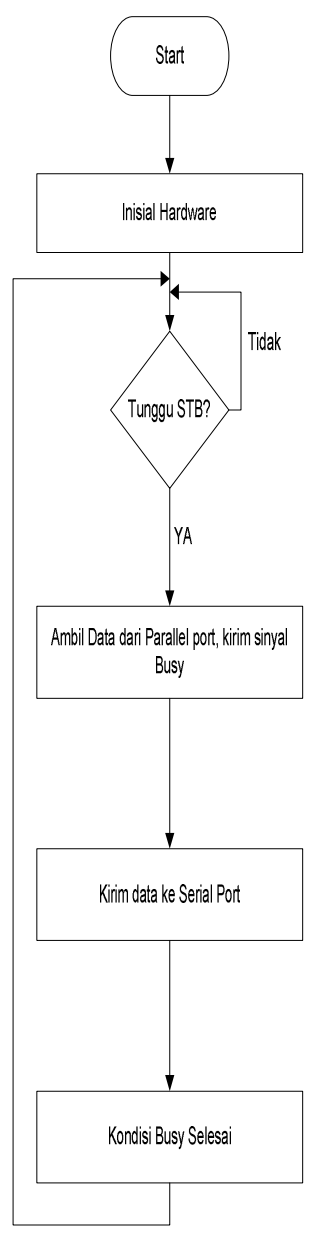

Gambar 10. Diagram Alir Pengambilan Data dari Parallel Port.

\subsection{Pengiriman Data ke Printer}

Proses yang terjadi pada pengiriman data ke printer hampir sama dengan proses pengambilan data dari parallel port menuju sistem pengendali-mikro. Dalam hal ini sistem pengendali-mikro bertindak sebagai virtual komputer. Diagram alir pengiriman data ke printer dapat dilihat pada Gambar 11. 


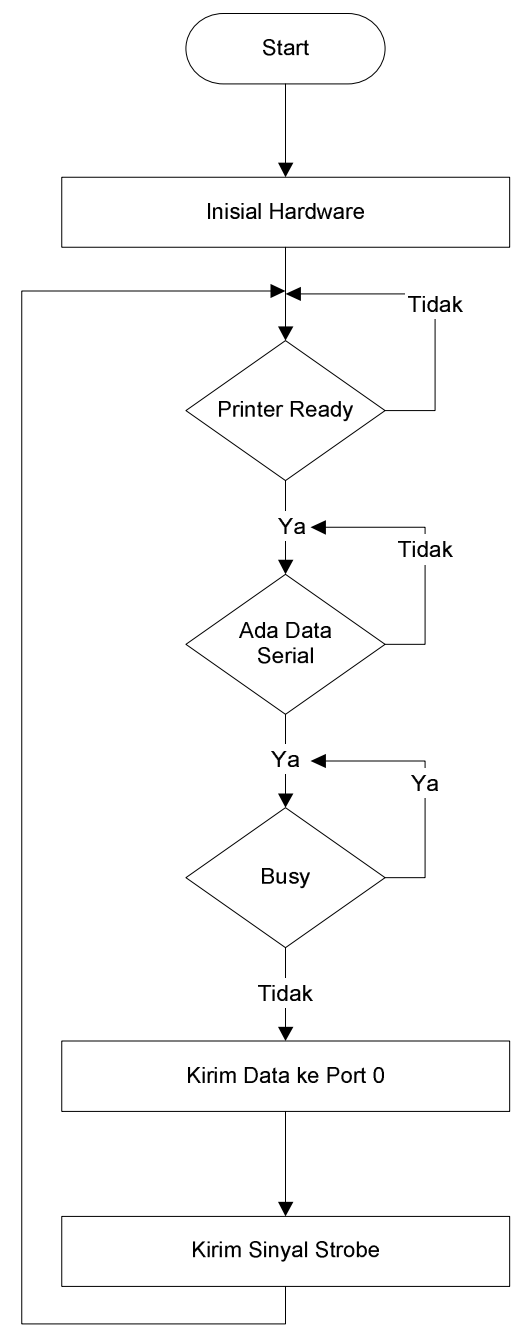

Gambar 11. Diagram Alir Pengiriman Data ke Printer.

\section{Pengujian}

\subsection{Pengujian Modul Pengendali-mikro}

Pengujian pengendali-mikro dilakukan dengan tujuan untuk mengetahui apakah perangkat keras dan perangkat lunak dari bagian pengendali-mikro dapat mengambil data dari parallel port dan mengirimkan data ke printer. Pengujian dilakukan dengan menggunakan sistem operasi Windows 98, windows ME, dan Windows XP.

Pengujian dilakukan dengan cara menghubungkan parallel port komputer menuju pengendali-mikro AT89S52, yang kemudian dihubungkan dengan pengendali-mikro yang terhubung dengan printer seperti yang ditunjukkan pada Gambar 12.

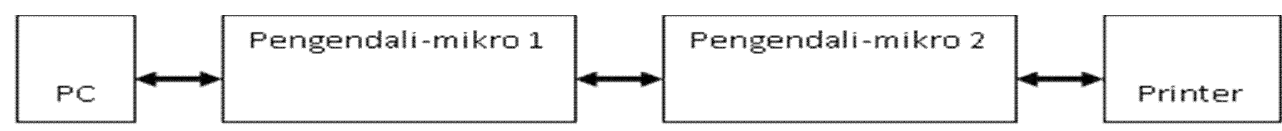

Gambar 12.. Bagan Pengujian Pengendali-mikro. 
Sistem operasi menganggap modul pengendali-mikro 1 sebagai printer, sehingga pengendali-mikro dapat mengambil data dari parallel port. Untuk modul pengendalimikro 2 yang terhubung dengan printer dilakukan dengan cara mengirimkan data yang diterima dari pengendali-mikro 1. Data yang diterima dapat tercetak dengan baik pada printer. Pada pengujian ini digunakan kabel serial (TX terhubung dengan RX) sebagai sarana transmisi data dari sistem pengendali-mikro 1 dan sistem pengendali-mikro 2 . Dari hasil pengujian yang diperoleh dapat diambil kesimpulan bahwa pada bagian pengendali-mikro (baik perangkat keras maupun perangkat lunaknya), sudah dapat bekerja dengan baik sesuai dengan yang diinginkan.

\subsection{Pengujian Modul ASK}

Pengujian modul Amplitude Shift Keying (ASK) TLP434 dan RLP434 dilakukan untuk mengetahui apakah modul dapat menerima atau mengirimkan data dengan baik. Cara menguji modul tersebut dilakukan dengan memberikan logika 1 atau 0 pada modul transmitter, kemudian sinyal tersebut diterima oleh modul penerima dan output-nya juga 1 atau 0 sesuai dengan logika yang dikirimkan. Untuk melakukan pengujian terhadap modul Amplitude Shift Keying (ASK) ini digunakan Function generator, Osiloskop dan Power supply.
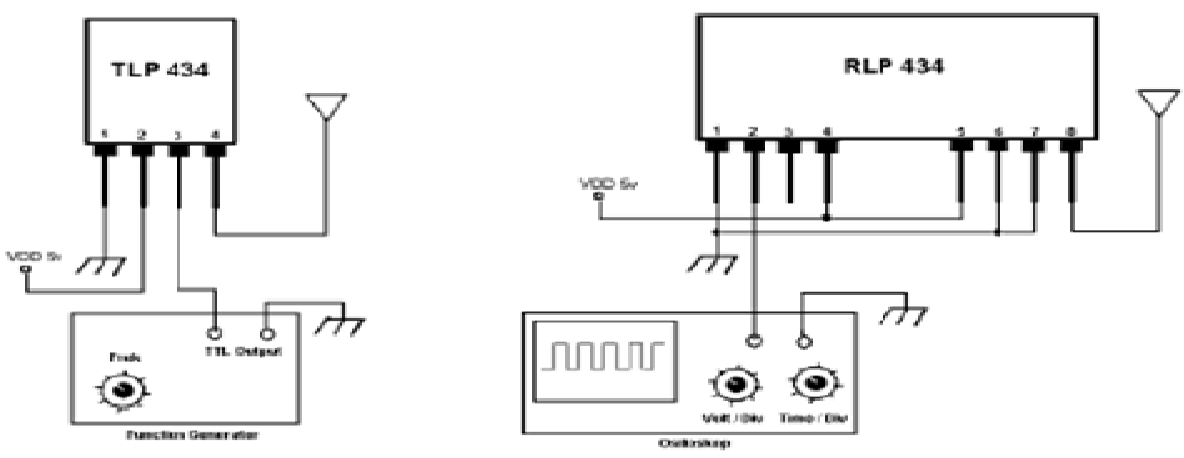

Gambar 13. Pengujian Modul ASK.

Pengujian dilakukan dengan menghubungkan keluaran modul ASK TLP434 (yang telah diberi masukan isyarat kotak) ke masukan ASK RLP434 seperti yang ditunjukkan pada Gambar 13. Pada Gambar 14 terlihat bahwa isyarat kotak keluaran modul ASK RLP434 (atas) mempunyai isyarat kotak yang sama dengan masukkan ASK TLP434 (bawah).

Modul Amplitude Shift Keying (ASK) yang digunakan mempunyai spesifikasi jarak pancar maksimum 100 meter jika tanpa halangan dan 30 meter di dalam gedung. Setelah dilakukan pengujian jarak dengan jarak 14 meter, modul ASK TLP434 dan RLP434 masih dapat bekerja dengan baik dengan kondisi tanpa halangan dan di dalam gedung. 


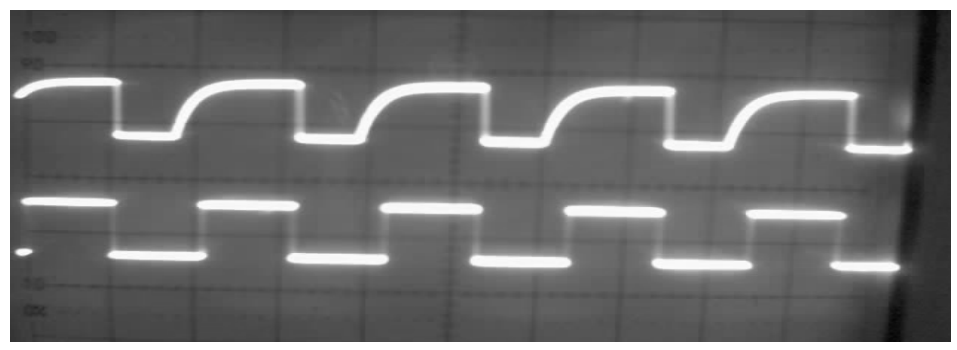

Gambar 14. Masukan ASK RLP434 dan Keluaran ASK RLP434.

\subsection{Pengujian Sistem Wireless Printer}

Pengujian Sistem wireless printer dengan Amplitude Shift Keying (ASK) dilakukan dengan menggunakan printer Canon BJC2100 SP, sedangkan sistem operasi yang digunakan adalah Windows XP. Untuk pengujian kecepatan cetak, printer melakukan pencetakan Gambar dengan resolusi 800 x 600. Dengan mengatur kualitas cetak normal, kecepatan yang didapat seperti terlihat pada Tabel 1 .

Tabel 1. Kecepatan Cetak Gambar.

\begin{tabular}{|l|c|}
\hline \multicolumn{1}{|c|}{ Koneksi Printer } & Waktu \\
\hline Kabel paralel & 1 menit 28 detik \\
\hline Wireless & 10 menit 3 detik \\
\hline
\end{tabular}

Untuk pengujian kecepatan cetak teks, printer melakukan cetak teks 1 halaman penuh A4. Dengan mengatur kualitas cetak normal, kecepatan yang didapat seperti terlihat pada Tabel 2.

Tabel 2. Kecepatan Cetak Teks.

\begin{tabular}{|l|c|}
\hline \multicolumn{1}{|c|}{ Koneksi Printer } & Waktu \\
\hline Kabel paralel & 32 detik \\
\hline Wireless & 2 menit 15 detik \\
\hline
\end{tabular}

Dari hasil pengujian didapat kecepatan cetak wireless printer dengan Amplitude Shift Keying (ASK) lebih lambat dibandingkan dengan menggunakan kabel. Hal ini disebabkan oleh delay yang terjadi dalam sistem pengendali-mikro baik dalam pengiriman dan penerimaan data.

\section{Kesimpulan}

Komunikasi data dari PC menuju printer dapat dilakukan secara wireless. Data dapat dikirim secara paralel maupun serial. Delay mempengaruhi kecepatan cetak printer wireless dengan ASK yang menggunakan modul TLP434 dan RLP434. Keberhasilan pengiriman data dipengaruhi oleh kualitas sinyal yang ditransmisikan. Alat yang direalisasikan dapat bekerja dengan baik sebagai wireless printer dengan ASK pada jarak 14 meter untuk kondisi tanpa halangan dan di dalam gedung.

\section{Daftar Pustaka}

[1] Mischa Schwartz, Transmisi, Informasi, Modulasi, dan Bising, Jakarta, Erlangga, 1986.

[2] Mackenzie, I. Scott, "The 8051 Microcontroler, 2nd Edition", Prentice Hall, 1995.

[3] Stewart, James W, "Hardware, Software and interfacing 2nd Edition", Prentice Hall. 